\title{
Effects of Pilates Training on Lumbo-Pelvic Stability and Flexibility
}

\author{
Sureeporn Phrompaet, MSc; Aatit Paungmali*, MPhty, PhD; Ubon Pirunsan, MPhty, PhD;
}

Patraporn Sitilertpisan, MSc, PhD

Authors' Affiliation:

Neuro-Musculoskeletal and Pain Research Unit, Department of Physical Therapy, Faculty of Associated Medical Sciences, Chiang Mai University, Chiangmai, Thailand

\footnotetext{
* Corresponding Author;

Address: Neuro-Musculoskeletal and Pain Research Unit, Department of Physical Therapy, Faculty of Associated Medical Sciences, Chiang Mai University, Chiangmai 50200, Thailand
}

E-mail: aatit@chiangmai.ac.th

Received: Oct 25, 2010

Accepted: Dec 12, 2010

Key Words: Pilates Training; Pilates-Based Exercises; Flexibility; Lumbo-pelvic stability; Exercise

\begin{abstract}
Purpose: This study was performed to assess and compare the effects of Pilates exercise on flexibility and lumbo-pelvic movement control between the Pilates training and control groups.

Methods: A randomized single-blinded controlled design was utilized in the study. Forty healthy male and female volunteers (mean age $31.65 \pm$ 6.21 years) were randomly divided into Pilates-based training (20 subjects) and the control groups (20 subjects). The Pilates group attended 45-minute training sessions, 2 times per week, for a period of 8 weeks. Flexibility and lumbo-pelvic stability tests were determined as outcome measures using a standard "sit and reach test" and "pressure biofeedback” respectively at 0,4 and 8 weeks of the study.

Results: The results showed that the Pilates training group improved flexibility significantly $(P<\mathbf{0 . 0 0 1})$ during time intervals. This effect was also significantly greater than the control group for both 4 weeks and 8 weeks of the training period $(P<0.001)$. There were $65 \%$ and $85 \%$ of the subjects from Pilates group passing the lumbo-pelvic stability test at 4 and 8 weeks of training periods respectively. No subjects from the control group passed the test at any stages.

Conclusions: Pilates can be used as an adjunctive exercise program to improve flexibility, enhance control-mobility of trunk and pelvic segments. It may also prevent and attenuate the predisposition to axial musculoskeletal injury.
\end{abstract}

Asian Journal of Sports Medicine, Volume 2 (Number 1), March 2011, Pages: 16-22

\section{INTRODUCTION}

egmental stability and mobility control of the core $\checkmark$ body (i.e., lumbo-pelvic control) as well as flexibility of the body parts accentuate peak performance and prevent musculoskeletal injury ${ }^{[1]}$. Improper activation and poor control of deep trunk muscles (i.e., TrA, MF) exist in asymptomatic individuals showing inability to control lumbo-pelvic stability, which is the early detecting sign for the back problems $^{[2,3]}$. Remarkably, the dysfunction and delayed onset of $\operatorname{Tr} \mathrm{A}^{[4]}$ and atrophy of $\mathrm{MF}^{[5]}$ appear in people with low back pain. Consequently, CNS is not able to control these muscles in feed-forward manner. These changes cause instability of the spine. In addition to repetitive contraction, muscles will generate pulling 
stress upon the proximal attachments during movement which affects directly joints and soft tissues surrounding the spine as a result of strain and degeneration ${ }^{[6]}$.

Flexibility is a crucial element of fitness to gain optimal musculoskeletal function enhancing peak performance $^{[7]}$. Forward bending is a combination of lumbar flexion and pelvic tilting ${ }^{[8]}$. Tightness of hamstring muscles may restrict pelvic tilting due to their attachment to the ischial tuberosity on pelvis ${ }^{[9]}$. Hamstrings tightness and low back flexibility are also associated with low back pain ${ }^{[10,11]}$.

Pilates is an exercise program as a core stability approach to augment the neuromuscular system to control and protect the core body or spine. This method is a comprehensive body-mind conditioning, which coordinates core stabilizing exercise with mind and breath control challenging by flowing movement of the whole body ${ }^{[12,13]}$. Since a Pilates approach focuses on core body exercise and breath control, it facilitates activation of transversus abdominis, diaphragm, multifidus and pelvic floor muscles. Incorporation of these muscles contributes to stability of the lumbopelvic region. Pilates exercise has been claimed to be a successful program for health promotion, rehabilitation and athletic training. The study by Harrington and Davies supported that Pilates method improved trunk control ${ }^{[2]}$. Regarding the benefits of Pilates for flexibility, the study by $\mathrm{Kish}^{[14]}$ indicated that Pilates-based method significantly improved functional flexibility of the adductors and hip flexor muscles. However, the study by Wimer ${ }^{[15]}$ showed that there was no change of flexibility after Pilates training in older adults. These study's findings require further investigation into its effective implication.

So far, there have been limited reports on the therapeutic effects of Pilates training on lumbo-pelvic control and flexibility outcomes. Many studies have been poorly controlled and relatively small in sample size. Therefore, the purpose of this study was to assess and compare the effects of Pilates exercise on flexibility and lumbo-pelvic stability.

\section{METHODS AND SUBJECTS}

\section{Design:}

In this randomized controlled single-blind study, participants were divided randomly into Pilates-based and control groups using conceal envelop. An independent investigator who evaluated outcomes did not know the condition of group randomization.

\section{Subjects:}

Forty healthy male and female volunteers were recruited from the community setting in the northern part of Thailand from March 2006 to September 2009 and were equally randomized into 2 groups (i.e., Pilates and control). All participants were healthy and did not practice any kind of exercises or sport activities more than 20 minutes per session and 2 times per week. The characteristics of participants are indicated in Table 1.

\section{Procedure:}

Each participant gave an informed consent prior to entry into the study, and the ethical clearance was approved by the Institutional Human Research Ethics Committee (ethical approval number: 0515(012).1/ Res 037). Pilates-based group attended 45-minute training sessions, twice a week, for 8 weeks. The Modification of Pilates-based training was a comprehensive Mat Pilates-based concept ${ }^{[16]}$ that consisted of initial period

Table 1: Demographic characteristics of subjects are represented as mean (SD)

\begin{tabular}{|lccc|}
\hline Characteristic & Pilates group & Control group & P.Value \\
\hline Age (years) & $33.2(6.15)$ & $30.1(6.03)$ & 0.1 \\
Gender & $\begin{array}{c}\text { Male=10 } \\
\text { Female=10 }\end{array}$ & $\begin{array}{c}\text { Male=10 } \\
\text { Female=10 }\end{array}$ & 1 \\
\hline Weight (kg) & $60.6(10.68)$ & $57.7(13.05)$ & 0.2 \\
Height (cm) & $163.8(5.54)$ & $161.0(7.13)$ & 0.4
\end{tabular}


(0-4 $4^{\text {th }}$ week) and advanced period $\left(4^{\text {th }}-8^{\text {th }}\right.$ week $)$. For the control group, subjects were permitted to do normal activities including exercise and sport activities but not more than 20 minutes per session and 2 times per week. For ethical issues, the Pilates program was also introduced to the control group at the end of the study.

\section{Outcome measures:}

Lumbo-pelvic stability was assessed using pressure biofeedback unit (Chattanooga Group, Inc). The testing procedure followed the Harrington and Davies ${ }^{[2]}$ and Jull et al ${ }^{[17]}$. The flexibility was evaluated by the sit and reach test. This testing has commonly been used to assess low back and hip joint flexibility ${ }^{[7]}$. Both lumbopelvic stability and sit and reach test for both studied groups were evaluated at 0,4 and 8 weeks of training duration. Chi-square test was used to determine a pass/fail in the lumbo-pelvic movement control at significance level of 0.05 . In addition, the change in flexibility data was analyzed using ANOVA, and the post-hoc tests were determined using t-test with correction for family wise error rate $(P \leq 0.016)$.

The reliability of outcome tests was conducted before the trial. The intra-tester reliability for lumbopelvic was demonstrated in excellent kappa statistical score (kappa>0.95). Intraclass correlation coefficients $\left(\mathrm{ICC}_{[3,1]}\right)$ for sit and reach test was 0.94 and standard error of measurements (SEMs) was minimal at $0.5 \mathrm{~cm}$.

\section{RESULTS}

All subjects completed the 8-week trail according to the study protocol. Fifteen subjects of the Pilates training group attended $100 \%$ (16) of training sessions. Four subjects presented $93.75 \%$ (15 sessions) and only one subject attended $75 \%$ (12 sessions) of sessions.

\section{Lumbo-pelvic stability:}

The percentage of subjects from both groups who passed the lumbo-pelvic stability test is presented in Table 2. Pre-training or at the baseline period, there were no subjects in Pilates or control groups who passed the test. In Pilates group, there were $65 \%{ }^{[13]}$ and
$85 \%{ }^{[17]}$ of the subjects who passed the lumbo-pelvic stability test at 4 and 8 weeks of training period respectively. All subjects who passed the test in the $4^{\text {th }}$ week passed the test in the $8^{\text {th }}$ week as well. It was found that there were significant differences between the percentage of passing the test during 4 weeks and 8 weeks of training in comparison with the baseline data (0-week). In contrast, no subjects in control group passed the lumbo-pelvic test at any stages of study $(0$, $4^{\text {th }}$ and $8^{\text {th }}$ weeks). The results demonstrated that number of subjects passing the lumbo-pelvic stability test from the Pilates training group was significantly greater than that of the control group $(\mathrm{P}<0.001)$ (Fig. 1 , Table 2).

\section{Flexibility (sit and reach test):}

In the Pilates group, the measure score of sit and reach test from baseline ( 0 week), $4^{\text {th }}$ and $8^{\text {th }}$ weeks were $27.69 \mathrm{~cm}, 31.77 \mathrm{~cm}$ and $34.89 \mathrm{~cm}$ respectively. Pilates group improved flexibility significantly $\left(\mathrm{F}_{(2,38)}=54.71\right.$; $P<0.001)$ during the time interval of 0,4 and 8 weeks. In the control group, the mean baseline ( 0 week) of sit and reach test was $22.74 \mathrm{~cm}$. The sit and reach test at 4 and 8 weeks of the study were $22.51 \mathrm{~cm}$ and $22.91 \mathrm{~cm}$ respectively. However, obtained data showed that there was no significant $\left(\mathrm{F}_{(2,38)}=0.165 ; P=0.849\right)$ difference in flexibility of the control group at baseline (0 week), 4 and 8 weeks of the study. The improvement of flexibility in Pilates group was also significantly greater than control group in both 4 and 8 weeks training sessions $\left(\mathrm{F}_{(1,38)}>15.06 ; \mathrm{P}<0.001\right)$ (Fig. 2).

\section{DISCUSSION}

In current study, we hypothesized the paramount benefits of Pilates for physiological functions "whether Pilates-based conditioning significantly improves the lumbo-pelvic stability and flexibility better than the control group". The results of the present study demonstrated that the lumbo-pelvic stability and flexibility of the Pilates group significantly improved in comparison with the control group. These results are coterminous with previous studies ${ }^{[2,14,18]}$. 
Table 2: Percentage (number) of subjects passed the lumbo-pelvic stability test from the Pilates training and control groups during the period of study (0, 4 and 8 weeks)

\begin{tabular}{lcccc}
$\begin{array}{l}\text { Interval } \\
\text { measures }\end{array}$ & $\begin{array}{c}\text { Pilates training } \\
\text { group }\end{array}$ & $\begin{array}{c}\text { Control } \\
\text { group }\end{array}$ & $\begin{array}{c}\text { Chi-square comparing } \\
\text { the two groups }\end{array}$ & P.Value \\
\hline 0 week & $0 \%(0)$ & $0 \%(0)$ & 0.00 & 1.000 \\
\hline 4 week & $65 \%(13)$ & $0 \%(0)$ & 19.25 & $<0.001$ \\
\hline 8 week & $85 \%(17)$ & $0 \%(0)$ & 29.56 & $<0.001$ \\
\hline
\end{tabular}

\section{Lumbo-pelvic stability:}

Logical explanations for improvement of lumbo-pelvic control are relevant to specific concepts of Pialtesexercise in terms of the role and neural control mechanism of local muscles, motor learning and physiological response to specific volume of Pilates program. The concept of Pilates exercise focuses on core or powerhouse and breath control that activates local muscles, especially transversus abdominis, internal oblique, diaphragm, lumbar multifidus and pelvic floor muscles. Currently, scientific data show that these muscles have primary role in stabilizing the lumbo-pelvic system ${ }^{[4,19,20]}$. The stability of lumbopelvic system is also dependent on the central nervous system to determine the requirements of stability by pre-programmed $\operatorname{Tr} A$ contraction to stabilize the spine prior to trunk perturbation from limbs movement and external load to the body's parts ${ }^{[4]}$. By the Pilates method, CNS may enhance the control of the spine when the trunk is challenged by internal and external forces (e.g., as a result of the reactive forces from moving upper and lower limbs during each position of exercise).

Considering motor leaning described by Magill ${ }^{[21]}$, it can be implied into: 1) Cognitive stage; the participants paid attention to cognitive oriented problem needed high awareness in order to isolate TrA contraction during each position of practices, using the verbal cues including internal and external feedback to detect errors, and followed the instructor step by step. 2) Associative stage; participants learned to associate some environmental cues with the movements by minimizing errors and perform consistently control

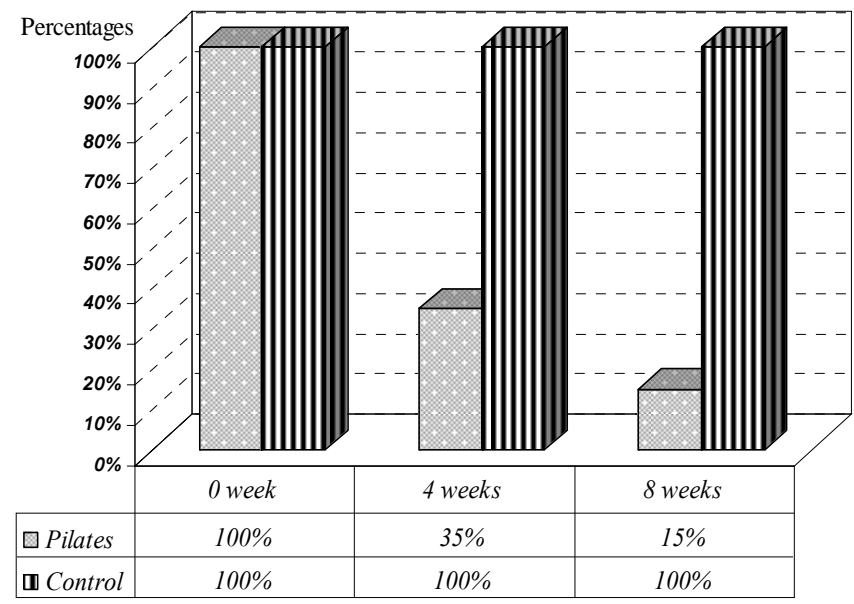

Fig. 1: The bar graph represents the percentages of the Pilates training and control groups who failed the lumbo-pelvic stability test 


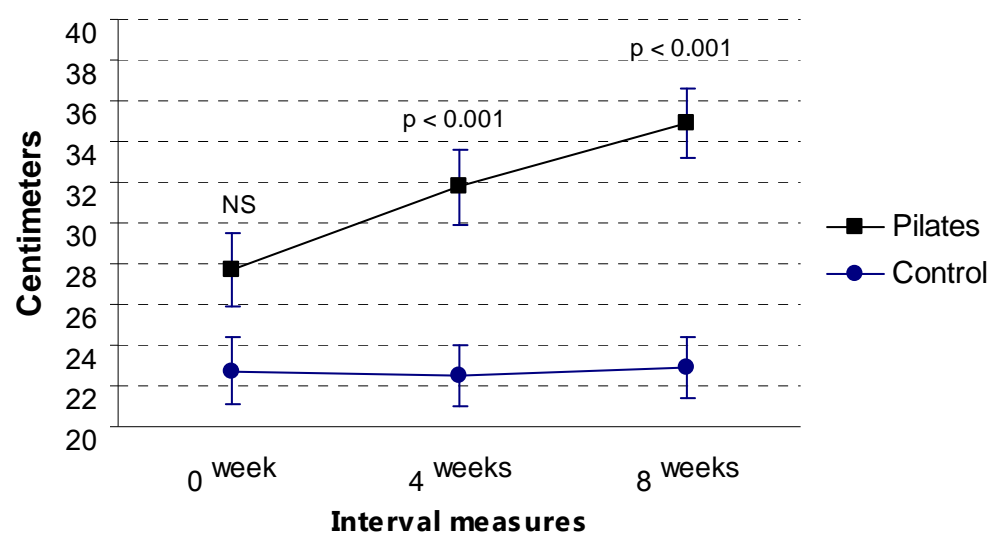

Fig. 2: Mean \pm SEM of flexibility at baseline ( 0 week), 4 and 8 weeks between Pilates training and control groups

Note: Statistically significant level between groups (post-hoc analysis using t-test with correction for family wise error rate $(P \leq 0.016))$

contraction of TrA when the movement is challenged. Participants could detect errors and correct them themselves. Once association took place, the new movement sequence might become automatic.

The volume of Pilates exercise in this study was specific to cause physiological effects. Prolonged exercise (approximately 45 minutes) with low to moderate intensity is specific to promote strength, endurance, and neuromuscular control of the local muscles (i.e., transversus abdominis, pelvic floor and multifidus muscles) ${ }^{[23]}$. The local muscle largely consists of type I or slow-twist skeletal muscles. Type I fibers contain plentiful mitochondria, high amount of oxidative enzymes and high density of capillaries. These characteristics make them well adapted for endurance activities over 30 minutes such as Pilates exercise prescription in this trial. Size or crosssectional area of type I muscles increase as a result of increasing mitochondria, membranous and muscle filaments within the fibers ${ }^{[22]}$. Thereby, the strength and endurance of type I fibers occur showing improvement of lumbo-pelvic stability. Improved recruitment and synchronous stimulation of these motor units also account for increased muscle strength ${ }^{[23,26]}$.

The result of this study is in agreement with the previous study by Harrington and Davies ${ }^{[2]}$.
Interestingly, there were no participants passing lumbo-pelvic stability test in any of Pilates and control groups. It shows that asymptomatic individuals present inability of transversus abdominis to control the lumbo-pelvic stability. Lack of transversus abdominis activation for maintaining lumbo-pelvic stability in normal subjects was also reported in the study of Harrington and Davies ${ }^{[2]}$. The authors suggested that it might be due to improper TrA recruitment to stabilize the lumbar system, which can cause lumbar problems in the future (e.g., instability, pain).

\section{Flexibility:}

This study provides remarkable insight into the potential benefits of Pilates exercise for flexibility. The Pilates exercise prescription in this study was successful to enhance flexibility component in agreement with flexibility exercise prescription by $\mathrm{ACSM}^{[7]}$. This effect can be explained by specific concept of Pilates approach, mechanical response of both contractile and non-contractile tissues and neurophysiological response to specific volumes of Pilates exercise prescription in current study.

The concepts of Pilates exercise focus on flowing movement throughout the whole body. The intensity of movement is the final range of motion at a tightness point without discomfort. The frequency of practice is 
twice a week with 5 repetitions per position. These dosages of exercise are appropriated to promote flexibility according to many researches that suggest that 2-10 repetitions of stretching exercise for 10-15 seconds during a 4-10-week period of training contributes to developing flexibility ${ }^{[7,24]}$. Pilates method is a combination of static and dynamic stretching exercises which are proper and safe to provide an increasing flexibility ${ }^{[25]}$. Improving back and legs flexibility in this study is supported by the Pilates studies of Segal et al ${ }^{[18]}$ and Kish ${ }^{[14]}$. Kish's study $^{[14]}$ indicated the effects of Pilates exercise on improving hip adductors and flexors flexibility. Notwithstanding available evidences flavoring in benefits of Pilates exercise on flexibility, the study by Wimer $^{[15]}$ demonstrated unclear effects of Pilates training on flexibility in elder subjects. The unchanged flexibility after 10 weeks of Pilates training may be due to the factor of aging.

Neurophysiological properties of contractile tissues response to stretching exercise. When Pilates stretching position is applied, slow stretch to soft tissues (i.e., skin, tendon, joint capsule) and muscles activates Golgi tendon organ. This sensory receptor detects differences in the tension generated by either passive stretch or active muscle contraction. Golgi tendon organ inhibits alpha motor neuron activity as a result of decreased tension in muscles, permitting sarcomeres to lengthen ${ }^{[22]}$.

Besides the change of mechanical characteristics of contractile and non-contractile tissues during slow stretch, the effect can be explained by stress-strain curve, when gentle force is applied perpendicular to the cross-sectional area of the tissues. Initially, the wave collagen fibers are straightened. With additional tension stress, recoverable deformation occurs in the elastic range. Reaching the elastic limits results in heat release (hysteresis) and new length. Additionally, the creep phenomenon can occur with low-magnitude and repetition of Pilates exercise in 45-minute sessions, twice a week, for 8 weeks. Repetitive stress will increase the plastic deformation of tissues usually in the elastic range, allowing a gradual rearrangement of collagen fibers and ground substance. The stretching positions applied after warm-up phase to raise the soft tissues temperature emphasize the creep effect and lengthen the soft tissues ${ }^{[26]}$. Another explanation of these changes is associated with viscoelastic properties. Shrier and Gossal ${ }^{[27]}$ postulated that the effects of stretching exercise increased range of motion owning to either a decrease in viscoelasticity or an increase in stretch tolerance. Kubo et al. also supported this view with showing static stretching affected the viscoelasticity of tendon structures ${ }^{[28]}$.

Some limitations of the study should be noted. This study determined only the short-term effects of the Pilates training program on lumbo-pelvic stability and flexibility in healthy subjects. Effects on other outcome measures, long-term follow up, and other populations such as musculoskeletal conditions warrant further investigations.

\section{CONCLUSION}

The results of this study indicate the specificity of Pilate-based exercise as an appropriate volume to contribute to physiological benefits which occur after 4 weeks of training as follows:

1. Enhances lumbo-pelvic stability

2. Improves flexibility of lower back and legs

The results of this study suggest that Pilates method can be used as an adjunctive exercise program for improving flexibility, encouraging control-mobility of trunk and pelvic segments. It may also help in preventing and attenuating the injury and dysfunction of musculoskeletal system.

\section{ACKNOWLEDGMENTS}

We would like to express our gratitude to participants of the study and the Thai Health Promotion Foundation for supporting the grant for this study.

Conflict of interests: The authors declare that they have no conflict of interests. 


\section{REFERENCES}

1. Panjabi MM. Clinical spinal in stability and low back pain. J Electromyogr Kinesiol 2003;13:371-9.

2. Harrington L, Davies R. The influence of Pilates training on the ability to contract the Transversus abdominis muscle in asymptomatic individuals. J Body Work Mov Ther 2005;9:52-7.

3. Standaert CJ, Weinstein SM, Rumpeltes J. Evidence-informed management of chronic low back pain with lumbar stabilization exercises. Spine J 2008;8:114-20.

4. Hodges PW. Changes in motor planning of feed-forward postural responses of the trunk muscles in low back pain. Exp Brain Res 2001;141:261-6.

5. Yoshihara K, Shirai Y, Nakayama Y, Uesaka S. Histochemical changes in the multifidus muscle in patients with lumbar intervertebral disc herniation. Spine 2001;26:622-6.

6. Hodges PW. Core stability exercise in chronic low back pain. Ortho Clin North Am 2003;34:245-54.

7. ACSM. ACSM's Health-Related Physical Fitness Assessment Manual. 3 ed. Philadelphia: Lippincott Williams \& Wilkins. 2010.

8. Nordin M., Frankel V. Basic Biomechanics of the Musculoskeletal System. Philadelphia: Lippincott Williams \& Wilkins. 2001.

9. Gajdosik R, Albert C, Mitman J. Influence of hamstring length on the standing position and flexion range of motion of the pelvic angle, lumbar angle, and thoracic angle. J Ortho Sports Phys Ther 1994;20:213-9.

10. Battie M, Bigos S, Fisher L. Anthropometric and clinical measures as predictors of back pain complaints in industry: a prospective study. J Spinal Dis 1990;3:195-204.

11. Jones M, Stratton G, Reilly T, Unnithan V. Measurement error associated with spinal mobility measures in children with and without low-back pain. Acta Pediatr 2002;91:1339-43.

12. Muscolino E. Pilates and the "powerhouse"-1. J Body Work Mov Ther 2004;8:15-24.

13. Latey P. Updating the principles of the Pilates method-Part 2. J Body Work Mov Ther 2002;6:94-101.

14. Kish R. The Functional Effects of Pilates Training on Dancers. PhD thesis. California State University; Department of Kinesiology. 1998.

15. Wimer J. The effects of functional resistance training on muscular strength, balance and functional abilities of older adults. PhD thesis. San Diego State University; Department of Exercise and Nutritional Sciences, 1999.

16. Bass M, Robinson L, Thomson G. The Complete Classic Pilates Method. Basingstoke, Oxford: Macmillan. 2004

17. Jull G, Richardson C, Toppenberg R, et al. Towards a measurement of active muscle control for lumbar stabilization. Aus J Physiother 1993;39:187-93.

18. Segal A, Neil H, Basford R. The effects of Pilates training on Flexibility and body composition: An observational study. Arch Phys Med Rehab 2004;85:1977-81.

19. Vasseljen O, Fladmark AM. Abdominal muscle contraction thickness and function after specific and general exercises: A randomized controlled trial in chronic low back pain patients. Man Ther 2010;15:482-9.

20. Critchley D. Instructing pelvic floor contraction facilitates transversus abdominis thickness increase during low-abdominal hollowing. Physiother Res Inter 2002;7:65-75.

21. Magill R. Motor Learning Concepts and Applications: The Stage of Learning. 6 ed. Boston: McGraw-Hill. 2001.

22. McArdle WD, Katch FI, Katch VL. Exercise Physiology: Energy, Nutrition, and Human Performance. 6 ed. Philadephia: Lippincott Williams \& Wilkins. 2007.

23. Richardson C, Hodges PW, Hides J. Therapeutic Exercise for Spinal Segmental Stabilization in Low Back Pain: Scientific Basis and Clinical Approach. Edinburgh: Churchill Living Stone, 2004.

24. Roberts J, Wilson K. Effect of stretching duration on active and passive range of motion in the lower extremity. Br $J$ Sports Med 1999;4:259-63.

25. Bandy W, Irion J, Briggler M. The effect of static and dynamic range of motion training on the flexibility of the hamstring muscles. $J$ Ortho Sports Phys Ther 1998;27:295-300.

26. Liemohn W. Exercise Prescription and the Back. New York: McGraw-Hill. 2001.

27. Shrier I, Gossal K. Myths and truths of stretching. Individualized recommendations for healthy muscles. Phys Ther Sports Med 2000;28:1-7.

28. Kubo K, Kanehisa H, Fukunaga T. Effect of stretching training on the viscoelastic properties of human tendon structures in vivo. $J$ App Physiol 2002;92:595-601. 